\title{
Some syntactic features of relative constructions in the Greek New Testament
}

Herman C du Toit

Research Fellow, Department of New Testament, University of the Free State, South Africa

E-mail: hcdutoit@icon.co.za

\begin{abstract}
In the Greek New Testament, relative sentences that are introduced by relative pronouns alone, apart from the adverbial uses, are the most frequent subordinate sentence type. The research reported on in this paper aimed to investigate and describe a number of syntactic features of relative constructions in the Greek New Testament, taking account, among others, of some typological parameters that have been developed in the general linguistics literature for these constructions.
\end{abstract}

The results indicate that relative constructions in the Greek New Testament have a variety of features, all of which have counterparts in some modern (or other ancient) languages, despite the differences. The relative sentence in the Greek New Testament is mostly postnominal, and the relative pronoun-type is used in those cases for encoding the role of the coreferential element in the relative sentence. Phrases expressing a variety of syntactic functions in a sentence (e.g. subject, direct object, etc.) are accessible to relativisation, that is, they can be represented by relative pronouns. Nominal elements serve mostly as antecedents of relative sentences, although sentences appear in that function as well.

A variety of syntactic types of relative sentences can be distinguished, including the prenominal participial, postnominal finite/participial, circumnominal, free relative, adverbial, prejoined, postjoined, sentential and conjoined types. These can be linked in a systematic way to the four functions of relative sentences in the New Testament, i.e. identifying, appositive, adverbial and continuative.

Relative sentences also play a role in communicative strategies. Prejoined relative sentences, for example, are most suitable for exposition and theme-building, especially in the correlative diptych construction.

Keywords: Relative sentence, relative construction, syntax, Hellenistic Greek, New Testament 


\section{Introduction}

The relative construction (RC), which could be defined simplistically as consisting of an antecedent and a relative sentence (RS), is a pervasive phenomenon in the languages of the world. It is also a common feature of Hellenistic (and Classical) Greek. In the Greek New Testament (NT), for example, RSs introduced by the relative pronoun (RP) alone, apart from the adverbial uses, are the most frequent subordinate sentence (Robertson 1919: 954). This is also reflected in the lengthy entry for the RP ö ( "who") in the NT Concordance of Aland (1983: 998-1011). Not all the examples listed by Aland are instances where ö ("who") functions as an RP, but the overwhelming majority are. ${ }^{1}$

The RC in NT (and Classical) Greek exhibits a variety of functional, syntactic and stylistic features. With respect to the functions of the RS, it was argued by Du Toit (1984: 2014) that the following functional types of RSs could be distinguished in the NT: (1) Identification of a referent together with or without an overt (i.e. phonetically realised) antecedent (“identifying RS"); ${ }^{2}$ (2) Giving background information in the form of a parenthesis or additional information (“appositive RS") 3 ; (3) Qualifying a verb with regard to time, cause or manner ("adverbial RS"); and (4) Functioning as a conjoined sentence ("continuative RS"). NT (and Classical) Greek has these functions in common with numerous modern languages (and Latin), despite some differences.

This paper discusses a number of syntactic features of RCs, and a few stylistic rules that involve syntactic mechanisms. Some syntactic types of RSs are identified and linked to the functions mentioned above. The discussion also takes into account, among others, a number of useful typological parameters that have been developed for RCs in general linguistics. These are briefly discussed below.

\section{Typological parameters of RCs}

Comrie (1989: 144) ${ }^{4}$ distinguishes a number of cross-linguistic typological parameters for RCs (in his terminology, relative clauses), ${ }^{5}$ and makes a major typological division between RCs with embedded and adjoined RSs: embedded RSs are constituents of the main sentence (in Comrie's terminology, main clause), whereas adjoined RSs are "adjoined" or "attached" to the

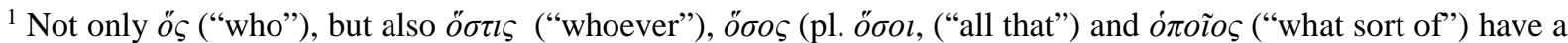
number of other uses in the NT, in addition to their use as RPs. For examples, see Du Toit (1984: 74-76, 86-89 [fnn. 17-21]).

2 This function of the RS is usually referred to as "restrictive" in more recent literature on the Greek NT (cf. Wallace 1996: 662, Porter 2013: 86, Voelz 2006: 401-403, etc.). So also in general linguistics (cf. Lehmann 1984: 262-268, De Vries 2006: 234-235; 264, etc.).

${ }^{3}$ The term "non-restrictive" is often used for this function, for example by Chomsky (1977: 65), Porter (2013: 86), Voelz (2006: 401-403), etc. Other terms used include "descriptive" and "explanatory” (Comrie 1989: 138).

${ }^{4}$ Although somewhat dated, Comrie (1989) gives a reliable and accessible overview of several parameters relating to word order in relative constructions, and is still widely cited in the literature on these constructions. Cf. also Van Valin and LaPolla (1997: 503-505, 509-604), Radford (2009: 226-7), etc.

${ }^{5}$ Comrie's definition of RCs includes not only RCs with finite RSs, but also non-finite (for example, participial) constructions such as the string Passengers leaving on flight 738 in the sentence Passengers leaving on flight 738 should proceed to the departure lounge. It includes also restrictive attributive adjectives like good in The good students all passed the examination (Comrie 1989: 143-144). Comrie uses the term "relative clause" occasionally to refer only to the RS, and not to the whole RC (cf. Comrie 1989: 145 [para.1], 151 [para. 2]).
} 
main sentence. ${ }^{6}$ He distinguishes the following parameters that relate mainly to RCs with embedded RSs (Comrie 1989: 145-160). These are briefly discussed in 2.1-2.4 below:

\subsection{Word order and RC-types ${ }^{7}$}

According to Comrie (1989: 145), the two most widespread types of RCs are the postnominal type, where the RS follows its head, and the prenominal type, where the RS precedes its head. Cf. the English sentence in (1a) with its Turkish equivalent in (1b) (examples from Comrie 1989: 142):

(1) a. $I$ ate [the potato [that Hasan gave to Sinan]]. ${ }^{8}$

b. [[Hasan-ın Sinan-a ver -diğ-i ] patates-i ] yedim

Hasan-of Sinan-to give -his potato-ACC I.ate ${ }^{9}$

"I ate the potato that Hasan gave to Sinan."

In (1a) the RS is postnominal, following the head the potato, whereas the RS precedes the head patatesi ("potato") in the Turkish equivalent in (1b). In both examples in (1), the head noun is outside the RS. ${ }^{10}$

Comrie (1989: 145-146) also distinguishes a third type of word order, where the head of the $\mathrm{RC}$ occurs inside the RS, the so-called internal-head or circumnominal type. There is no overt expression of the head in the main sentence. Cf. the following example from Bambara (Comrie 1989: 145):

(2) Tyغ̀ be [[n ye so min ye $]]$ dy man the PRS. I PST. house see build

"The man is building the house that I saw."

In this example, the whole RC functions as direct object of the main sentence, but the sense is that of an RS. ${ }^{11}$

\footnotetext{
${ }^{6}$ This correlates with the distinction made by Lehmann (1984: 48, 122, 146) between RSs that are eingebettet (“embedded”) and angeschlossen (“adjoined”), although Lehmann’s definitions are more explicit. According to Lehmann (1984: 48), embedded RSs that are nominalised are immediate constituents of the nominal. In the case of adjoined RSs, there are no intervening nodes between the RS and the topmost sentence (Lehmann 1984: 122). An embedded subordinate sentence falls in a syntactic category, for example, an NP or an Adverbial (Lehmann 1984: 146).

${ }^{7}$ It should be noted that this parameter deals only with the relative order of the antecedent - in Comrie's (1989) terms, head - the RP and the RS within RCs, and not with other aspects of word order.

${ }^{8}$ To simplify the discussion and for ease of reference, the following conventions are followed in numbered examples such as (1): In the first line of each example, the RS is indicated by square (= [ ]) brackets and the RC by italicised square (= [ ]) brackets. In numbered Greek examples, the element in the RC (normally an N, but also a nominalised QNT, DEM, D, etc.), which usually determine the number and gender of the RP, is italicised. Italisation is not used where the RS is introduced by indeclinable elements, such as relative adverbs, fixed phrases, etc., since concord rules do not apply in such cases.

${ }^{9}$ ACC is the abbreviation used for "accusative case". The other abbreviations used in the glosses are as follows: DAT-dative case, F-feminine gender, GEN-genitive case, M-masculine gender, NOM-nominative case, PRTpresent tense, PST-past tense, RP-relative pronoun, SG-singular, VOC-vocative case, NEUT-Neuter gender.

${ }^{10}$ Van Valin and LaPolla (1997: 498) refer to this type of construction as "externally headed relative clauses".

${ }^{11}$ Comrie (1989: 146) points out that there are potential problems in working out which of the NPs within the RS is to be interpreted as its head in this type of construction, and its function within the RS. In the Bambara example in (2) above, the relative marker min is placed after the NP that is head of the RS, but in some languages, for
} 
Van Valin and LaPolla (1997: 503-504) distinguish a fourth type, namely headless RCs, ${ }^{12}$ as in the following English examples:

(3) a. I can't remember [[who Jose saw $]]$.

b. [[What Mary bought]] is mystery to me.

c. Robin could not identify [[who had talked to Kim at the party]] to the police.

In cases like these, RSs are not nominal modifiers, as there is no head noun. Free relatives constitute referring expressions in their own right (Van Valin and LaPolla 1997:504).

\subsection{Encoding the role of the head in the RS}

According to Comrie (1989: 147), encoding of the role of the head in the RS is one of the most significant typological parameters cross-linguistically. He discusses four major types of encoding, namely non-reduction, pronoun-retention, relative-pronoun and gap (Comrie 1989: 147-153): In the non-reduction type, the head noun of the RC appears in unreduced form in the $\mathrm{RS}$, in the normal position and/or with the normal case-marking of an NP expressing that function in the RS (cf. the example in (2) from Bambara).

In the pronoun-retention type, the antecedent occurs in the RS in pronominal form, for example, as a personal pronoun. This type occurs in non-standard varieties of English, as illustrated in the following example (Comrie 1989: 147):

(4) This is [the road [where I know where it leads]].

The element it indicates the position that is relativised and enables retrieval of the information that relativisation took place of the subject of the indirect question clause. In many languages, this type of encoding is the conventional way of forming RCs. In Persian, for example, pronounretention must be used for relativisation of all grammatical relations other than subject and direct object. Cf. the following example of relativisation of the indirect object (Comrie 1989: 148):

(5) Man [zan -i-rā [ke Hasan be u sibe zamini dād]] misěnāsam

I woman ACC. that Hasan to her potato gave I-know

"I know the woman to whom Hasan gave the potato."

In (5), it would be impossible to omit be u ("to her") or $u$ ("her”).

\footnotetext{
example in Imbambura Quechua, there is no such marker, and RSs can be ambiguous as to which NP is the head. The conceptualisation of "NP" has undergone several non-trivial changes since the generative approach was introduced in the late 1950s. Based on pioneering work by, among others, Abney (1987), it is currently generally accepted that an NP invariably forms part of a larger nominal phrase headed by an (overt or covert) determiner (D). Simplifying greatly, a nominal expression like the man would thus be analysed as a DP, with the NP man representing the complement of the D the. For further discussion, cf. e.g., Haegeman (1994: ch. 11) and Culicover (1997: ch. 3). It has since been argued that the DP itself forms part of a larger nominal phrase, one that is headed by a functional category referred to as a "light noun"; cf. e.g. Chomsky (2006) and Oosthuizen (2013). However, the term "NP" will be used below when referring to nominal expressions for the sake of keeping the discussion as non-technical as possible.

12 Sometimes referred to as “free relative clauses” (Radford 2009: 227), or simply “free relatives” (De Vries 2006: 237). The latter term is used in this paper.
} 
Encoding by means of an RP is a type commonly found in European languages, but it is not particularly frequent across the world's languages as a whole (Comrie 1989: 149). ${ }^{13}$ In this type of encoding, a pronoun occurs in the initial position in the RS and indicates the role of the head of the RS. ${ }^{14}$ Cf. the following examples from Russian (Comrie 1989: 149):

$$
\begin{aligned}
& \text { a. [devuška, [kotoraja prišla]] } \\
& \text { girl who.NOM. arrived } \\
& \text { "the girl who arrived" } \\
& \text { b. [devuška, [kotoruju ja videl]] } \\
& \text { girl who.ACC. I saw } \\
& \text { "the girl whom I saw" }
\end{aligned}
$$

In both examples, the Russian pronoun kotor- ("who") is in sentence-initial position, and encodes the role of the head noun in the RS.

In the gap type of encoding, there is no overt indication of the role of the head within the RS. An example is that in the initial position in English RSs, where it relativises subjects or objects. Cf. the following English examples (Comrie 1989: 151):

(7) a. [the man [that gave the book to the girl]] (subject relativised)

b. [the book [that the man gave to the girl]] (direct object relativised)

According to Comrie (1989: 152), the interpretation of the role of the head noun within the RS is determined in such languages by strategies that range from those based on syntactic properties of the language to knowledge of real-world properties. In English, for example, where the basic word order is SVO (= Subject-Verb-Object), an RC like the man that saw the girl can only be interpreted as relativising the subject of the RS. The direct object position is already filled by the girl, whereas the subject position preceding saw is empty (ibid.).

Schwartz (1971: 142) makes a correlation between the way of encoding the role of the head in the RS and post- and prenominal word order types in the RC. In languages where the RS is postnominal, a variety of syntactic patterns occur, which are listed in (8a-e) below. (In these examples, and those in (9a,b), NP refers to the antecedent of the RS, WH to an RP or relative adverb, $\varnothing$ to the absence of the relativised NP in the RS, That to an invariable relative particle or complementiser, and PRO to a resumptive pronoun in the RS.)
(8) a. NP WH ...
b. NP That ...ø....
c. NP That ... Pro
d. NP ... ø....
e. NP That WH ....

\footnotetext{
${ }^{13}$ Fiorentino (2007: 263) refers in this regard to the existence of an European Sprachbund ("linguistic league”), commonly called Standard Average European (SAE), which has a "core” area consisting of French, Dutch, German and Northern Italian dialects (i.e. Continental West-Germanic languages, Gallo-Romance and Gallo-Italic languages), and a "peripheral area" consisting of the other Romance and Germanic languages, the Balkan languages and some Slavic (especially West-Slavic) languages. It also includes Western Finno-Ugrian languages (Finnish, Hungarian) and an Afro-Asiatic language (Maltese). Fiorentino (2007) points out that even in the European languages, the RP-type proves to be less frequent, if spoken varieties of the languages are also considered.

${ }^{14}$ It should be noted that Comrie (1989) uses the term "head" here to refer to the relativised element inside the RS.
} 
In languages where the RS is prenominal, the relativised nominal is usually covert, that is, not phonetically realised, but may occasionally surface as a personal pronoun. An RC could have the following formats in these languages:
a. $\ldots \varnothing \ldots \mathrm{NP}$
b. ...PRO... NP

\subsection{The role of the head in the main sentence}

According to Comrie (1989: 153), in most of the world's languages, the role of the head noun in the main sentence (in Comrie's terminology, main clause) makes little or no difference to the particular RS-construction that is used. One of the exceptions is attraction in Latin and Greek, whereby the case-marking of the head-N of the RS is attracted into that of the head-N of the main sentence (and vice versa). Comrie (1989: 154) gives the following example from Ancient Greek:
(10) ek [tõn póleōn [hõn éxei]]
from the cities-GEN which-GEN he-has
"from the cities which he has"

In (10), the head-N of the RC, póleōn ("cities") is governed by the P ek ("from") and therefore in the genitive case. The RP hõn ("which") in the RS, which would usually be in the accusative case as direct object of the V éxei ("he has"), has been assimilated to the genitive case of the head-N.

\subsection{Accessibility to RS-formation}

A last parameter that is distinguished by Comrie (1989) is accessibility to RS-formation. He gives the following examples from English, where there is no restriction on RS-formation in simple RSs. One can relativise the subject, direct object, indirect object, object of a P, and the possessor in a possessive construction (Comrie 1989: 155):

(11) a. [the man [who bought the book from the girl]] SUBJECT

b. [the book [which the man bought for the girl]] OBJECT

c. [the girl [for whom the man bought the book]] OBJECT OF PREPOSITION

d. [the boy [whose book the man bought for the girl]] POSSESSOR

However, in many languages there are severe restrictions on relativisation, specifically with regard to the function of the expression that can be relativised. The ease of access to RSformation operates along the so-called "Accessibility Hierarchy", viz. subject $>$ direct object $>$ non-direct object (= indirect object/prepositional object [HC]) $>$ possessor, which is claimed to be valid cross-linguistically. ${ }^{15}$ Comrie (1989: 156) formulates the relevant language universal as follows:

If a language can form relative clauses on a given position on the hierarchy, then it can form relative clauses on all positions higher (to the left) on the

\footnotetext{
${ }^{15}$ The Accessibility Hierarchy was postulated by Keenan in a number of publications, e.g. Keenan $(1974,1975$ and 1976), Keenan and Comrie $(1977,1979)$ and Comrie and Keenan (1979). See also Lehmann (1984: 211-220) for a detailed discussion.
} 
hierarchy; moreover, for each position on the hierarchy, there is some possible language that can relativize on that position and all positions to the left, but on no position to the right.

These remarks can be clarified with reference to the following two examples. In a language such as Malagasy, a VOS (= Verb-Object-Subject) language, only subjects can be relativised:

(12) [ny mpianatra [izay nahita ny vehivavy]]

the student that saw the woman

"the student who saw the woman" (Comrie 1989: 156)

In a language like Kinyarwanda, relativisation is possible of subjects and direct objects. However, it is not possible to use an expression denoting instrument, like n-ikaramu ("with the pen”) in (13), to form an RC directly corresponding to the pen with which John wrote the letter.

(13) Yohani yanditse ibaruwa n -ikaramu

John wrote letter with-pen

"John wrote the letter with the pen" (Comrie 1989: 157)

\section{Some syntactic features of RCs in the NT}

\subsection{Introduction}

RCs in NT (and Classical) Greek commonly consist of an overt antecedent, followed by an RS. In some instances, the antecedent is covert, for example, in free relative constructions. ${ }^{16}$ With regard to encoding the role of the coreferential element in the RS, NT (and Classical) Greek uses the RP-type of encoding, which is commonly found in European languages such as Russian, French, German, the Northern Italian dialects, etc. ${ }^{17}$

The discussion below focuses mainly on examples where RSs are introduced by RPs and relative adverbs. A few references are also made to participial RSs. The RPs that are discussed

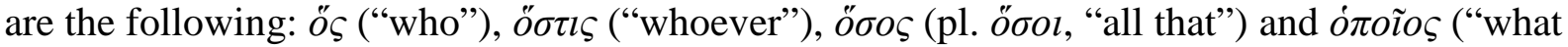
sort of"). ${ }^{18}$ The meanings of the definite $o \varsigma$ ("who") and indefinite $\delta \sigma \tau \iota \varsigma$ ("whoever") are often not distinguishable in the NT, and show variation between authors such as Matthew, Luke and Paul (Blass and Debrunner [1913] 1967: 152-153). RPs usually occur at the beginning of the $\mathrm{RS}$, a feature they share with other WH-words, such as relative ADVs, interrogative PRONs and interrogative As. ${ }^{19}$

\footnotetext{
${ }^{16}$ According to Boyer (1988: 236), there are 473 RSs (in his terms, relative clauses) in the NT, for which the antecedent is "lacking, left to be supplied, or understood".

${ }^{17}$ See section 2.2 (also fn. 14). In some instances, a pleonastic personal pronoun is used with the RP in the RS,

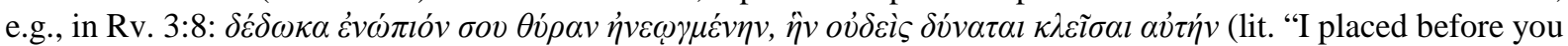
an opened door, which nobody can open it). This is due to Semitic influence in the NT, although it also occurs in classical and later Greek (cf. Danker 2000: 726; Blass and Debrunner [1913] 1967: 155).

${ }^{18}$ The status of $\dot{0} \pi \circ \tilde{i}_{0} \varsigma$ as an RP is uncertain.

${ }^{19}$ In instances where the RP is governed by a P, the P precedes, as in Acts 20:18d.: $\dot{\alpha} \pi \dot{o} \pi \rho \dot{c} \tau \eta \varsigma \dot{\eta} \mu \varepsilon \dot{\varepsilon} \rho \alpha \varsigma \dot{\alpha} \varphi$ ' $\tilde{\eta}_{\varsigma}$

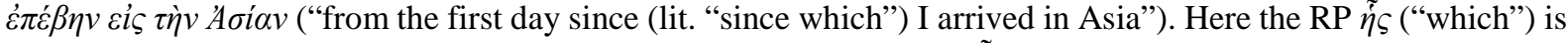
preceded by the P $\dot{\alpha} \varphi$ (= $\dot{\alpha} \pi \dot{o}$ "from") at the beginning of the RS $\dot{\alpha} \varphi$ ' $\tilde{\eta}_{\varsigma} \dot{\varepsilon} \pi \dot{\varepsilon} \beta \eta v \varepsilon i \zeta \tau \dot{\eta} v \dot{A} \sigma i \alpha v$ (lit. "from which I arrived in Asia"). In isolated cases, elements that belong semantically to the RS also appear to the left of the RP

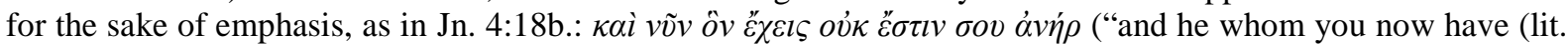


The gender and number features of an RP are usually determined by its head-N. The core could

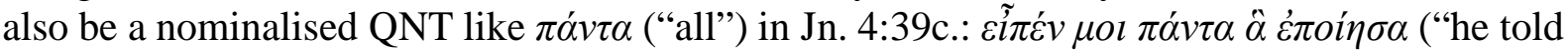

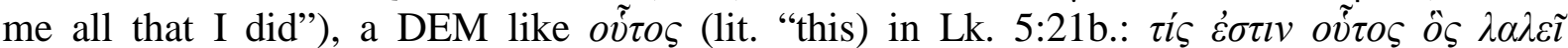
$\beta \lambda \alpha \sigma \varphi \eta \mu i \alpha \varsigma ;$ ("who is this man that speaks blasphemies?"), etc. ${ }^{20}$ The gender and number features of the RP are determined in a few instances by the constructio ad sensum ("construction according to sense"), which was a very widespread feature of Greek from early times (Blass and Debrunner [1913] 1967: 74). In a constructio ad sensum, semantic features take precedence

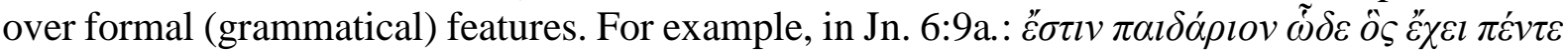

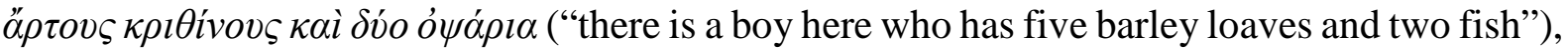

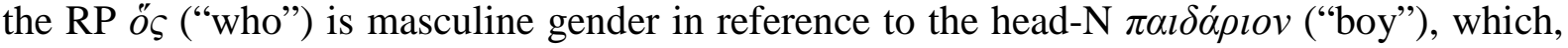
although grammatically neuter gender, refers to a male child.

The case of an RP is usually determined by its syntactic function inside the RS, i.e. whether it functions in the RS as subject, object, etc. In some instances, the case of the RP is assimilated to that of the head-N (or another nominalised element) by means of progressive assimilation,

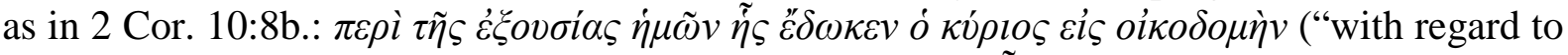
our authority which the Lord gave for building up”). The RP $\tilde{\eta} \varsigma$ (“which”), which would usually be in the accusative case as direct object of $\check{\varepsilon} \delta \omega \kappa \varepsilon v$ ("he gave"), is here in the genitive case, since it is assimilated by the case of the head-N $\dot{\varepsilon} \xi$ ovoi $\alpha \varsigma$ ("authority"). The head-N is in the genitive case, since it is governed by the $\mathrm{P} \pi \varepsilon \rho i$ ("with regard to").

NT (and classical) Greek is highly accessible to relativisation, in comparison with languages such as Malagasy and Kinyarwanda. ${ }^{21}$ Relativisation is possible of the subject, direct object, indirect object, in genitive constructions denoting possession, and in PPs. The use of the RP in some of these functions is illustrated below:

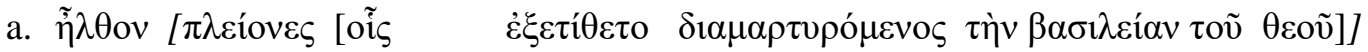

$$
\begin{aligned}
& \text { ēlthon pleiones hois exetitheto diamartyromenos tēn basileian tou theou } \\
& \text { they. many.A. to.whom. he. testifying.to the kingdom the of.God } \\
& \text { came NOM.PL.. RP.DAT. explained } \\
& \text { M. PL.M. }
\end{aligned}
$$

"many came to whom he explained and testified to the kingdom of God"

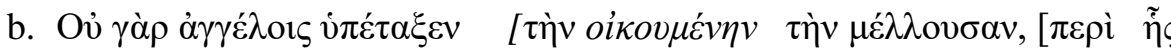
Ou gar angelois hypetaxen tēn oikoumenēn tēn mellousan, peri hēs (Ac. 28:23b.) not for to.angels he.subjected the world.N the coming about which. we.speak

$$
\text { ACC.SG.F. RP.GEN. }
$$$$
\text { SG.F. } \quad(P P)
$$

"He did not subject to the angels the world to come, about which we are speaking."

(Heb. 2:5)

\footnotetext{
and now whom you have) is not your husband"). In this case, the ADV ṽv ("now") has been moved out of the RS to the left of the RP $o v$ ("whom").

${ }^{20}$ In contrast to the conventional view of a head-N just mentioned, the head of an NP is restricted to a common noun or a proper noun within more recent generative models of grammar, including Minimalist Syntax. All other elements that could serve as nominal expressions on their own - e.g. quantifiers (QNTs), demonstratives (DEMs), possessive and personal pronouns (PRNs) - are claimed to belong to the broad category D (= Determiner) (cf. also fn. 11). On this view, the subject and direct object in a sentence such as He/both or her/everyone would each be analysed as a DP (= Determiner Phrase) taking he/both or herleveryone as its head, and lacking an NP.

${ }^{21}$ See section 2.4.
} 


\subsection{Embedded RSs ${ }^{22}$}

\subsubsection{RSs embedded in NPs}

Most RCs in the NT consist of a nominal antecedent with a postnominal RS and are NPs (hence NP-RCs). The NP-status of these RCs is borne out, for example, by the fact that they can function, like other NPs, as the subject, object or indirect object in a sentence, and also as the object of a P. This holds true of NP-RCs with overt and covert antecedents. In addition, the same elements that occur typically in NP-RCs with overt antecedents, also occur in other NPs. These include a head-N and/or one or more of the following elements: a QNT, DEM, D, A, an NP in the genitive, and a PP (when the NP and the PP qualify the core of the RC). Compare the following examples:

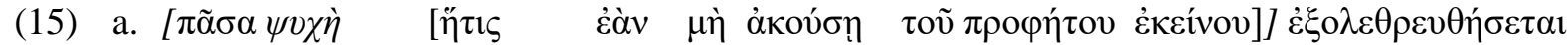 pasa psychē hētis ean mē akousē tou prophētou ekeinou exolethreuthēsetai every person.N. who.RP. - ever not he.listens. the prophet that he.will.be. NOM.SG.F. NOM.SG.F. to destroyed

"every person who does not listen to that prophet, will be destroyed"

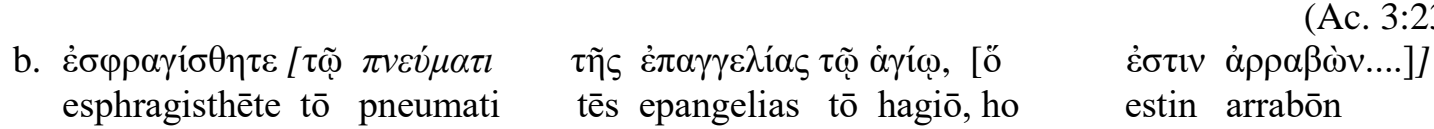
you.were. the with.Spirit.n the of.promise the holy who.RP. he.is guarantee sealed DAT.SG.N. NOM. SG. NEUT.

"you were sealed with the promised Holy Spirit (lit., Holy Spirit of the promise), who is the guaranteee of his glory".

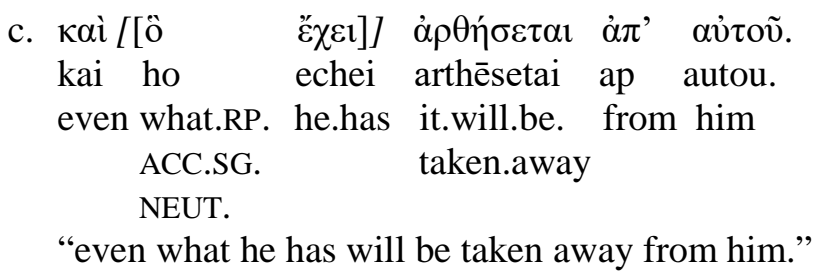

(Eph. 1:13c.-14)

(Mt. 13:12d.)

In (15a), the RC, which contains an overt head-N and postnominal RS, functions as subject of the sentence. So does the free relative construction in (15c). The RC in (15b) contains a number of elements that also occur in other NPs. For example, the head-N has a D $\tau \tilde{\omega}$ ("the"), and is qualified by the genitive construction $\tau \tilde{\eta} \varsigma \dot{\varepsilon} \pi \alpha \gamma \gamma \varepsilon \lambda i \alpha \varsigma$ (lit. "of the promise”) and the AP $\tau \tilde{\omega} \dot{\alpha} \gamma i \omega$ ("the holy").

The NP-RC in (15a) contains an embedded identifying RS, which is an immediate coconstituent of the NP and a co-constituent of the head-N. This is represented in simplified form in the diagram in (16): ${ }^{23}$

\footnotetext{
${ }^{22}$ See fn. 5 for Lehmann's (1984: 48) definition of an embedded RS.

${ }^{23}$ As was pointed out in fn. 12, it is generally accepted in more recent generative studies that an NP forms part of a larger nominal phrase, namely a DP, which is headed by an (overt or covert) determiner (D). This assumption is incorporated in the structures in (16) and (17).
} 
(16)

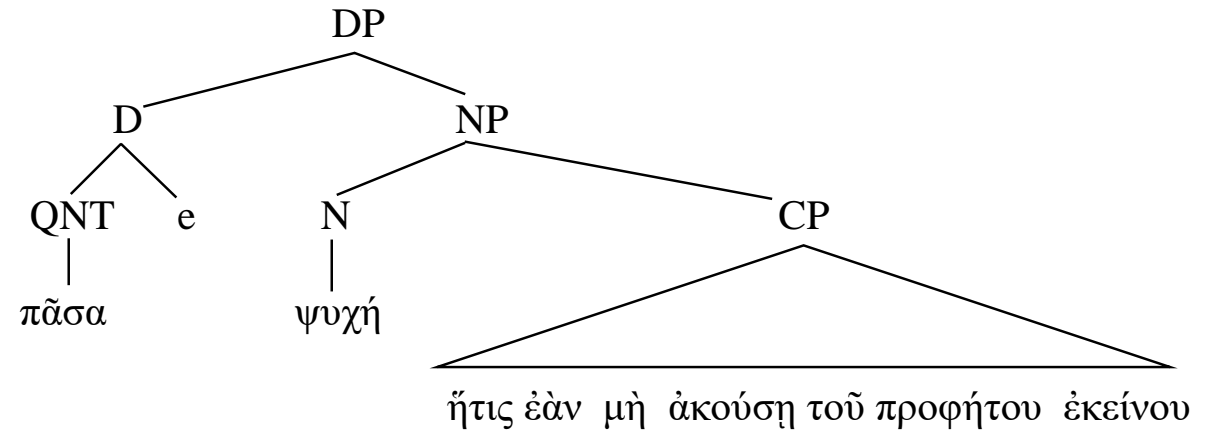

The RC in (15b) contains an appositive RS that occurs here in final position in the main sentence. According to Lehmann (1984: 272), appositive RSs in this position often function text-semantically like a main sentence and continues the discourse. ${ }^{24}$ In NP-RCs with an embedded appositive RS, the RS is an immediate constituent of the DP and a co-constituent of D. ${ }^{25}$ The simplified structure of the RC in (16b) could be represented as in (17):

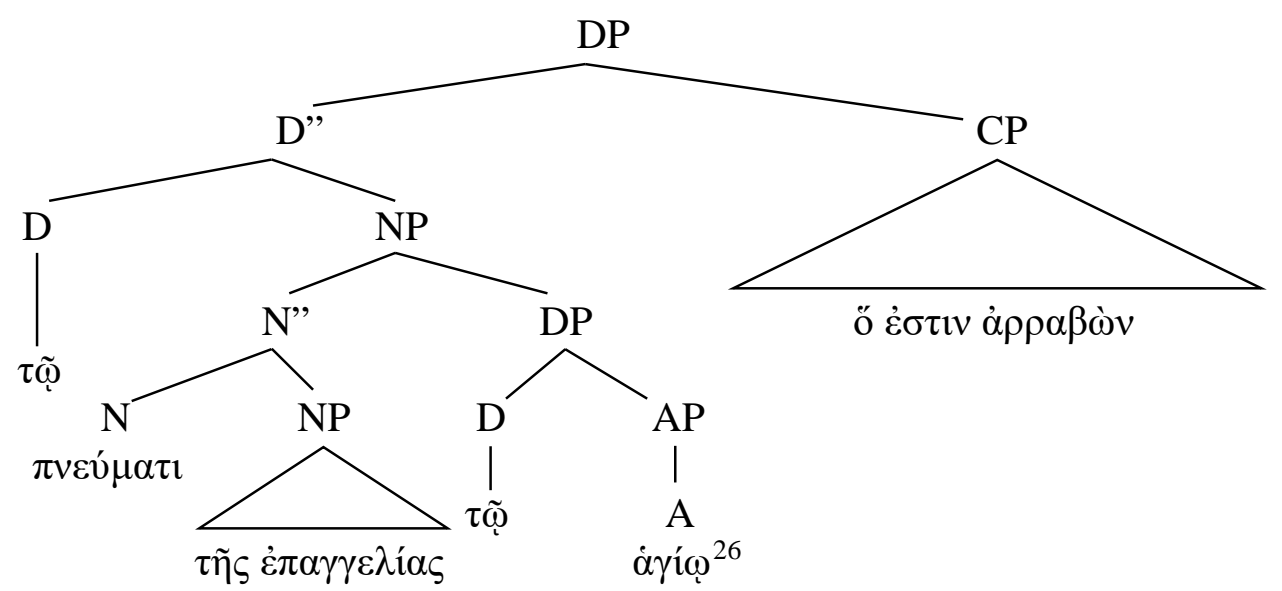

In all the above examples, the NP-RCs contain postnominal RSs whose verbs are in a finite mood. ${ }^{27} \mathrm{NT}$ (and classical Greek) also have NP-RCs that contain participial RSs, which can occur post- or prenominally. Participial RSs derive not only their number and gender features from the

\footnotetext{
${ }^{24}$ Lehmann (ibid.) makes a general distinction between appositive RSs that are parenthetisch ("parenthetical”) and those that are anknüpfend ("connected"). The criterion for this distinction is the position of the RS inside or at the end of the main sentence. The following examples illustrate the point (Lehmann 1984: 273): In the sentence Sie gab das Buch Emil, der es zur Bibliothek brachte ("she gave the book to Emil, who brought it to the library"), the appositive RS der es zur Bibliothek brachte ("who brought it to the library") is connected and continuative, functioning text-semantically like a main sentence. In contrast, an appositive RS that is parenthetical always gives background information, as in the sentence Emil, der das Buch zur Bibliothek brachte, muB es irgenwo auf dem Weg verloren haben ("Emil, who brought the book to the library, must have lost it somewhere on the way"). For more examples, see also Loetscher (1973: 366).

${ }^{25}$ An appositive RS refers anaphorically to the whole antecedent (D” in (17)), whereas an identifying RS refers only to the head-N, as in (16) (cf. Jackendoff 1979: 175; De Vries 2006: 251).

${ }^{26}$ According to Lehmann (1984: 148), RCs with an adnominal RS are endocentric constructions, consisting of two subconstituents, of which one, the structural nucleus, belongs to the same category as the higher constituent. In the

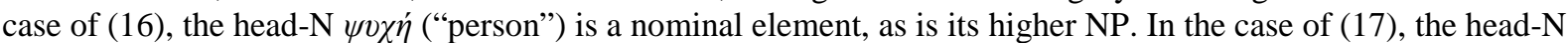
$\pi v \varepsilon v ́ \mu \alpha \tau$ ("Spirit") is also a nominal and in the same broad category as the higher nominal N".

27 The finite moods include the indicative, subjunctive, optative and imperative moods, in contrast to the infinitive and participle. In the finite moods, the verb suffixes indicate whether the subject is first, second, or third person, in addition to indicating number and voice. The finite moods used in RSs are the indicative and subjunctive moods.
} 
head-N like RPs, but also their case. Compare the examples of participial RSs in (18a-e) below (Hayes 2014: 103-104, 210, 123, 214):

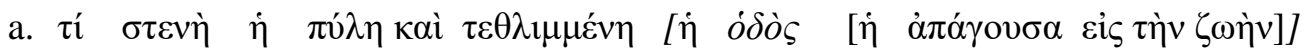

ti stenē hē pylē kai tethlimmenē hē hodos hē apagousa eis tēn zōēn

how narrow the gate and difficult the way.N the leading. to the life

$$
\text { SG.F PTCP.PRES. }
$$

ACT.NOM.

SG.F.

"how narrow is the gate and difficult the way that leads to life"

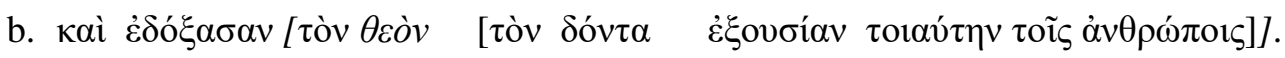

(Mt. 7:14a.)

kai edoxasan ton theon ton donta exousian toiautēn tois anthrōpois

and they. the God.N the having. authority such the to.men praised ACC.SG. given.

M. PTCP.AOR.

ACT. ACC.

SG.M.

"and they praised God, who had given such authority to men"

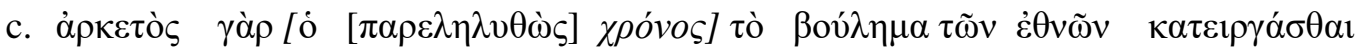

arketos gar ho parelēlythōs chronos to boulēma tōn ethnōn kateirgasthai

sufficient for the passed.PTCP. time.N the will the of. to.have.done

PRF.NOM. SG.M. Gentiles

SG.M.

"for the time that has passed was sufficient for doing the desires of the Gentiles"

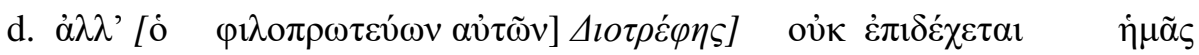

all ho philoprōteuōn autōn Diotrephēs ouk epidechetai hēmas

but the liking.to.be them Diotrephes.N. not he.acknowledges

leader.PTCP. NOM.SG.M

PRES.ACT.

NOM.SG.M.

"but Diotrephes, who likes to be their leader, does not acknowledge us"

In the above examples, the participial RSs in (18a,c) are postnominal and those in (18b,d) prenominal. Both post- and prenominal participial RSs could be identifying or appositive. The postnominal participial RS in (18a) is identifying, and the one in (18b) appositive, whereas the prenominal participial RS in (18c) is identifying, and the one in (18d) appositive. In all the examples, the participle agrees with its head- $\mathrm{N}$ in number, gender and case.

In addition to NP-RCs with embedded post- or prenominal RSs, NT (and classical) Greek also has instances of circumnominal RSs. ${ }^{28}$ In these cases the head-N of the RC has been moved to a position inside the RS by incorporation, which is an optional stylistic rule stemming from literary usage (cf. Rehkopf 1979: 243). The moved head-N ends up in the RS mostly in sentence-final position, or (in a few instances) directly after the RP. In the process, the head-N loses its D, if it had one. Not all head-Ns of NP-RCs can be incorporated, the condition being

\footnotetext{
${ }^{28}$ For the use of the term "circumnominal", see the reference to Comrie (1989: 145-146) in section 2.1, and his example of a circumnominal RS in Bambara in (2).
} 
that case-agreement should obtain between the head-N and the RP. Case-agreement between the head-N and the NP could result from case-assignment or from case-assimilation rules. Compare the following examples:

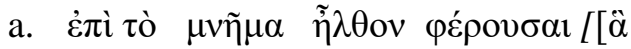
epi to mnēma ēlthon pherousai ha to the tomb they. carrying

$$
\begin{aligned}
& \text { went ACC.PL. prepared ACC.PL. } \\
& \text { NEUT. }
\end{aligned}
$$

"they went to the tomb, carrying the spices which they had prepared."

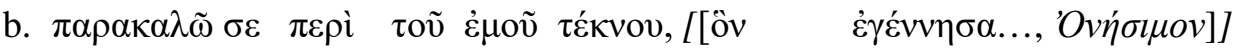 parakalō se peri tou emou teknou, hon egennēsa Onēsimon I.appeal you on. the my child.N whom. I.became. Onesimus.N to behalf. GEN.SG. RP.ACC. father of ACC.SG.M of N. SG.M.

(Lk. 24:1b.)

"I appeal to you on behalf of my child, Onesimus, whose father I became in my imprisonment."

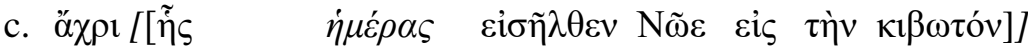 achri hēs hēmeras eisēlthen Nōe eis tēn kibōton

(Phm. 10)

In (19a), regular case-assignment rules assigned the same case (accusative) to the head- $\mathrm{N}$ of the

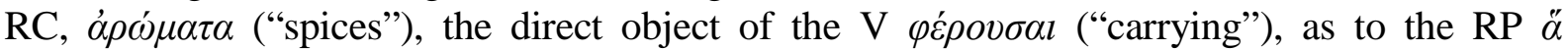
("which"), which is the direct object of the V iं The head-N, $\dot{\alpha} \rho \dot{\mu} \mu \alpha \tau \alpha$ ("spices"), was then incorporated into the RS, losing its D, and ends up in the RS in sentence-final position after iं $\tau$ í $\mu \alpha \sigma \alpha v$ ("they prepared"). In (19b), the head-N of the

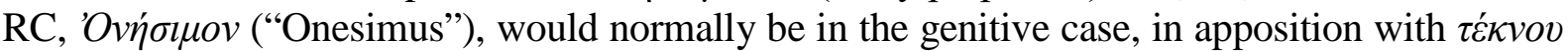

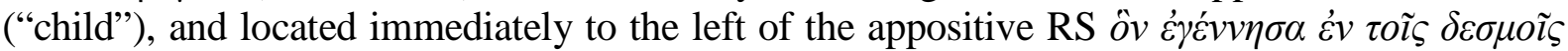
("whom I became the father of in my imprisonment"). In this instance, the (genitive) case of the head-N was regressively assimilated (in traditional Greek grammar, "attracted") into the accusative case of the RP $\hat{o v}$ ("whom"), which is the direct object of $\dot{\varepsilon} \gamma \varepsilon \dot{\varepsilon} v \eta \sigma \alpha$ ("I begot") in the

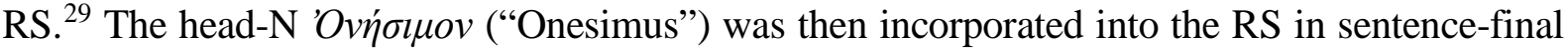

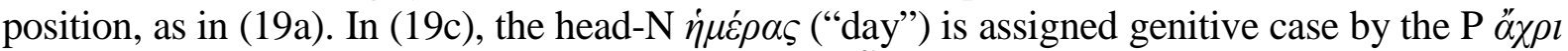
("until”), which is part of the main sentence. The RP $\tilde{\dot{\eta}} \varsigma$ ("on which”) (which would usually occur in the dative case in its temporal meaning, "on which"), has been drawn into the genitive case as a result of progressive assimilation by the head-N, $\dot{\eta} \mu \varepsilon \dot{\rho} \rho \varsigma$ (“day"). ${ }^{30}$ The head-N is then

\footnotetext{
${ }^{29}$ Attraction of the case of the head-N of the RC into that of the RP by means of regressive assimilation is known in traditional Greek (and Latin) grammar as attractio inversa ("reverse attraction”).

${ }^{30}$ Progressive assimilation, which is traditionally known in Greek and Latin grammar as attractio relativi ("attraction of the relative"), is an example of the influence of the head- $N$ of the antecedent in the main sentence on the form of the RS (cf. the general parameter in section 3.3). Blass and Debrunner ([1913] 1967: 153) point out that the RP ös ("who”) (not ö $\tau \iota \varsigma$, , “whoever”) is often assimilated to the case of its antecedent even though it should take another case, usually the accusative, in conformity with its use in the RS. According to Blass and Debrunner (ibid.), the NT, and especially Luke, conforms fully with classical use in this regard. They point out that exceptions occur if the relative clause is more clearly separated from its antecedent by additional nominal modifiers and the importance of
} 
incorporated into the RS, losing its D and appearing directly after the RP $\tilde{\eta} \varsigma$ ("which"). ${ }^{31}$ From the examples in $(19 a-c)$, it is clear that incorporation has the effect to convert postnominal RSs (both identifying RSs and appositive RSs) into circumnominal RSs.

The circumnominal RS also appears also in Latin, as shown in the following example from Lehmann (1984: 122):

(20) populo ut placerent [[quas fecisset fabulas]]

people so. they.may. which.RP. he.had. pieces.N.

that please ACC.PL.F. written ACC.PL.F.

"so that the pieces which he had written, may please the people"

(Ter. An.4)

The head-N fabulas ("pieces") appears in sentence-final position in the RS, similar to the head$\mathrm{N}$ in the Greek examples in (19a,b).

\subsubsection{RSs embedded in adverbials}

The RSs discussed above were all embedded in NPs and nominalised. Some free relatives that are introduced by relative adverbs, such as ö $\pi o v / o \tilde{v}$ ("where"), $\delta \theta \varepsilon v$ ("from where"), ö $\tau \varepsilon$ ("when”), etc., and occasionally by $\tau i \varsigma$ ("who, what"), ${ }^{32}$ are not immediate constituents of NPRCs, but embedded in an adverbial. Compare the examples in (21a,b):

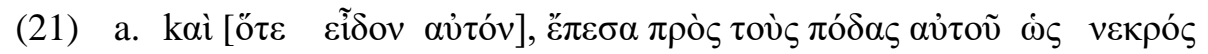
kai hote eidon auton, epesa pros tous podas autou hōs nekros. and when I.saw him I.fell at the feet of.him like dead.person "and when I saw him, I fell at his feet like a dead person."

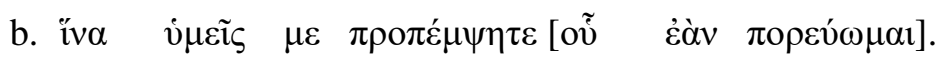

(Rv 1:17a.)

hina hymeis me propempsēte hou ean poreuōmai

so that you me you.could. where -ever I.go help.on.

"so that you can help me on my way, wherever I go."

(1 Cor 16:6b.)

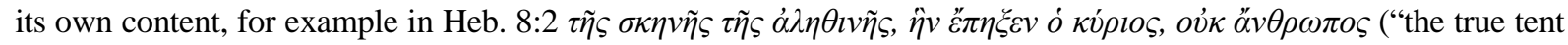
which the Lord set up, not a man") (ibid.). In some cases, progressive assimilation is obligatory, e.g. where an RC

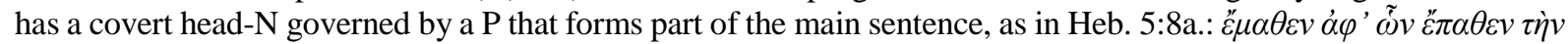

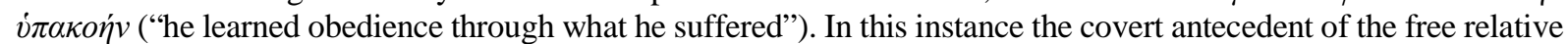
$\dot{\alpha} \varphi$ ' $\tilde{\omega} v \varepsilon \tilde{\varepsilon} \pi \alpha \theta \varepsilon v$ ("through what he suffered") is in the genitive case, because it is governed by the P $\dot{\alpha} \pi \dot{o}$ ("through") in the main sentence. The case of the RP $\ddot{\alpha}$ ("what"), which would usually be in the accusative case as direct object of the $\mathrm{V} \tilde{\varepsilon} \pi \alpha \theta \varepsilon v$ in the RS, is progressively assimilated into the genitive case by the genitive case of the covert antecedent. In a few instances, attraction of relative adverbs also takes place, e.g. in Mt. 25:24c: $\sigma v v \alpha \dot{\gamma} \gamma \omega v \quad \ddot{\theta} \theta \varepsilon v$

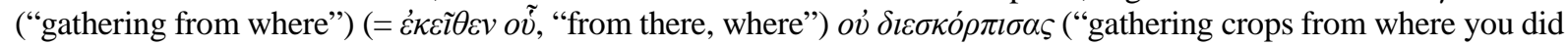
not scatter seed") (Blass and Debrunner ([1913] 1967: 225).

${ }^{31}$ The phrase $\ddot{\alpha} \chi \rho \imath \tilde{\eta} \dot{\zeta} \dot{\eta} \mu \varepsilon \dot{\varepsilon} \rho \alpha \varsigma$ (lit. “until on which day”) also appears in Lk. 1:20 and Ac. 2:1. However, if the P $\dot{\varepsilon} v$ ("on”) appears before $\dot{\eta} \mu \dot{\varepsilon} \rho \alpha$ ("day”), the head-N is not incorporated, and the phrase is always $\dot{\varepsilon} v \dot{\eta} \mu \varepsilon \dot{\varepsilon} \rho \alpha \tilde{\eta}$ (lit. "on the day on which"), for example in Mt 24:50, Lk. 1:20 (here plural). An incorporated head-N also appears directly

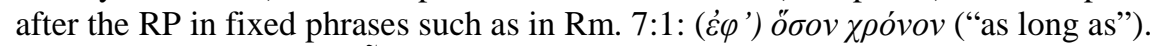

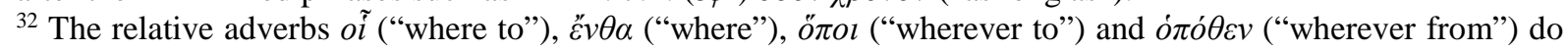
not appear in the NT as in Classical Greek.
} 
The RSs in $(21 a, b)$ have no relationship to a nominal antecedent, but denote time and place with regard to the verbs $\varepsilon^{\prime} \pi \varepsilon \sigma \alpha$ ("I fell”) and $\pi \rho о \pi \varepsilon \dot{\varepsilon} \mu \eta \tau \varepsilon$ ("you can help on"), respectively, like adverbs. Temporal RSs can also appear after the main sentence and not before it as in (21a) (for example, Heb. 7:10). Adverbial RSs of place can also appear before the main sentence instead of after it as in (21b), especially in correlative constructions (cf. Mt. 18:20).

Similar examples of adverbial uses of RSs also occur in English. See the examples in $(22 \mathrm{a}, \mathrm{b})$ (Radford 2009: 227):

(22) a. I will go [where you go].

b. I don't like [how he behaved towards her].

In (22a) the RS denotes place and in (22b) manner.

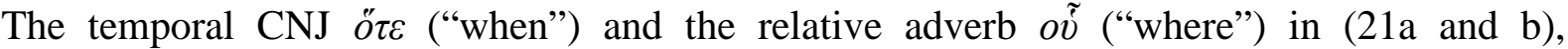
respectively, can also occur in RSs with an overt antecedent, in which case the RSs are identifying. Compare the examples in (23a and b) below where the RSs identify antecedents together with their head-Ns $\omega \rho \alpha$ ("time”) and $v \pi \varepsilon \rho \omega \omega$ ("upstairs room”), respectively:

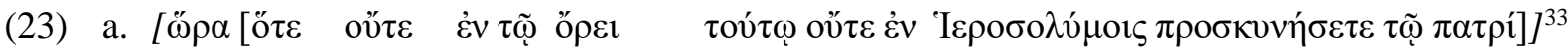
hōra hote oute en tō orei toutō oute en Hierosolymois proskynēsete tō patri time when. neither on the mountain this nor in Jerusalem you.will. the Father CNJ. worship

"a time when you will worship the Father neither on this mountain nor in Jerusalem"

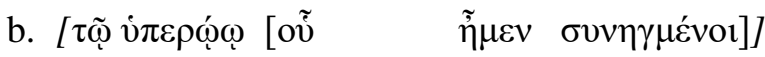

(John 4:21b.)

tō hyperōō hou ēmen synēgmenoi

the upstairs. where.REL. we. gathered

room ADV. were

"the upstairs room where we were gathered"

(Acts 20:8b.)

Compare also the German pairs in (24a,b) (Lehmann 1984: 318, 321):

(24) a. [wo es passiert ist]

where it happened

"where it happened"

b. [Ort, [wo es passiert ist]]

place where it happened

"place where it happened"

In (24a) the adverbial RS denotes place, whereas the RS in (24b) identifies the referent, together with its head-N Ort ("place").

Free relatives denoting time, cause, manner, etc., are sometimes introduced by fixed phrases that contain RPs, for example, PPs functioning as temporal phrases ( $\dot{\alpha} \varphi$ ' $\tilde{\eta} \varsigma$, ["from the time

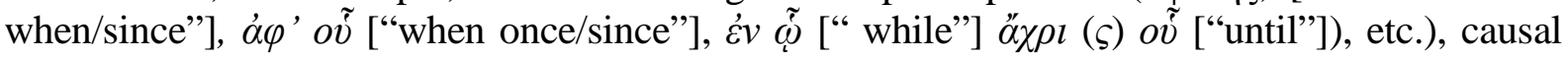

\footnotetext{
${ }^{33}$ The status of temporal sentences as a type of RS is supported by Blass and Debrunner ([1913] 1967: 192), who regard these in general as "only a special class of relative clause that exhibit the same constructions" (ibid.). Cf. also Boyer (1988: 238-240) and Lehmann (1984: 319-325). For a different view, see Robertson (1919: 953-954).
} 


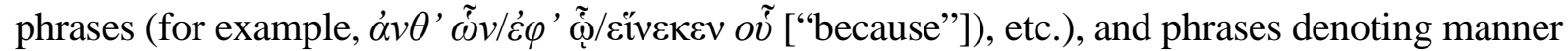

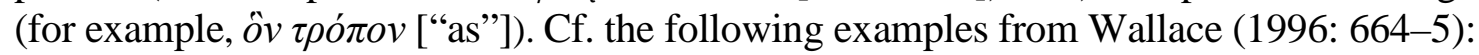

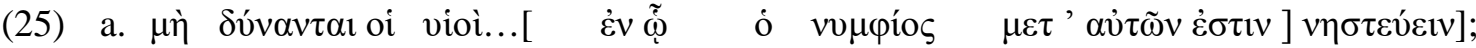
mē dynantai hoi huioi en hō ho nymphios met autōn estin nēsteuein? not they.can the attendants in which. the bridegroom with them he.is to.fast RP.DAT.

SG.M.

"Surely the bridegroom's attendants cannot fast while the bridegroom is with them?"

(Mark 2:19b.)

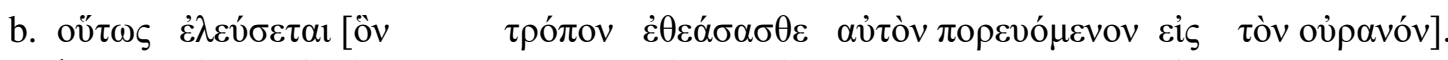
houtōs eleusetai hon tropon etheasasthe auton poreuomenon eis ton ouranon. in.this. he.will. in.which. way.N you.saw him going into the heaven way come RP.ACC. ACC.SG. SG.M. M.

"He will come in the same way as you saw him go into heaven."

(Acts 1:11c.)

In (25a), the fixed temporal phrase $\dot{\varepsilon} v \tilde{\dot{\omega}}$ ("while”) introduces a RS that indicates the temporal

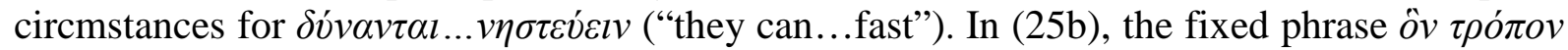
(“as”) introduces a RS indicating manner with regard to $\dot{\imath} \lambda \varepsilon \dot{v} \sigma \varepsilon \tau \alpha l$ ("he will come”).

\subsection{Adjoined RSs}

Within the category of adjoined RSs (introduced in section 2), Lehmann (1984: 48) makes a distinction between adjoined RSs that are vorangestellt ("prejoined") and those that are nachgestellt ("postjoined”). Prejoined RSs precede the main sentence, whereas postjoined RSs follow it. According to Lehmann (ibid.), an adjoined RS does not build an RC together with a nucleus (a head-N or other nominal element that can serve as antecedent) in the same syntactic sense as an adnominal RS. One cannot speak in this case of a head-N, but only of a nucleus in a semantic sense.

\subsubsection{Prejoined RSs}

Prejoined RSs result from a stylistic rule that places the RS in front of the main sentence. The main sentence usually has a correlative DEM (or a personal pronoun) that represents the RS. Consider the following example:

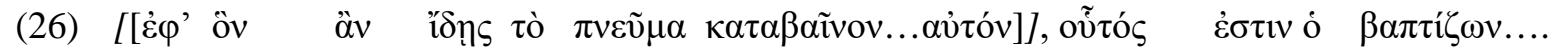
eph hon an idēs to pneuma katabainon auton houtos estin ho baptizōn on whom. -ever you. the Spirit descending. him this.DEM. he.is the baptising RP.ACC. See on NOM.SG.

SG.M.

"On whoever you see the Spirit descend and remain, this is the one who baptises with the Holy Spirit."

(Jn. 1:33b.)

In (26) the indefinite free relative precedes the main sentence oṽ ${ }^{\circ} \zeta \dot{\varepsilon} \sigma \tau \imath v \dot{o} \beta \alpha \pi \tau i \zeta \zeta \omega v . .$. ("he is the (lit.) baptising...”). The prejoined RS is an identifying RS, as is always the case in prejoined 
RSs (Lehmann 1984: 147). The correlative DEM oṽ RS in the main sentence. According to Lehmann (ibid.), there also exists an interdependence between a prejoined RS and its main sentence. Not only does the prejoined RS depend on the main sentence, but the main sentence also depends on the prejoined RS. However, the main sentence's dependence is not syntactic, but semantic, in the sense that it is related to the RS. This applies also to the main sentence in (26). ${ }^{34}$

In some cases, prejoined RSs occur together with their head-N, as in the following example:

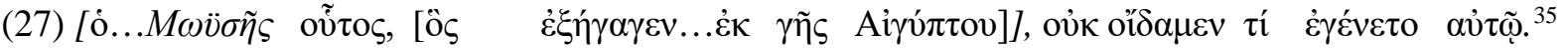
ho Mōusēs houtos, hos exēgagen ek gēs Aigyptou ouk oidamen ti egeneto autō the Moses.N this who.RP. he.led.out out. land of. not we. what it. to.him NOM.SG. NOM.SG. of Egypt know happened PERS. M. M. PRON. DAT. SG.M. "this Moses who led us out from the land of Egypt, we do not know what happened to him."

(Ac. 7:40)

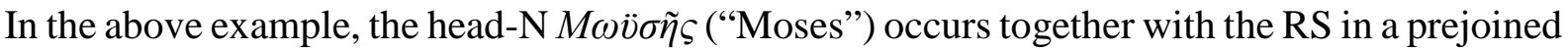
RC. Blass and Debrunner ([1913] 1979: 394) regard the use of the nominate case in the phrase

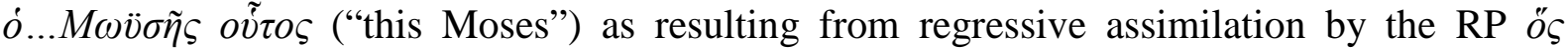
("who"). They also point out that a nominative without such attraction, the so-called nominativus pendens ("suspended nominative"), is rare. The only example given by Blass and Debrunner (ibid.) is the following:

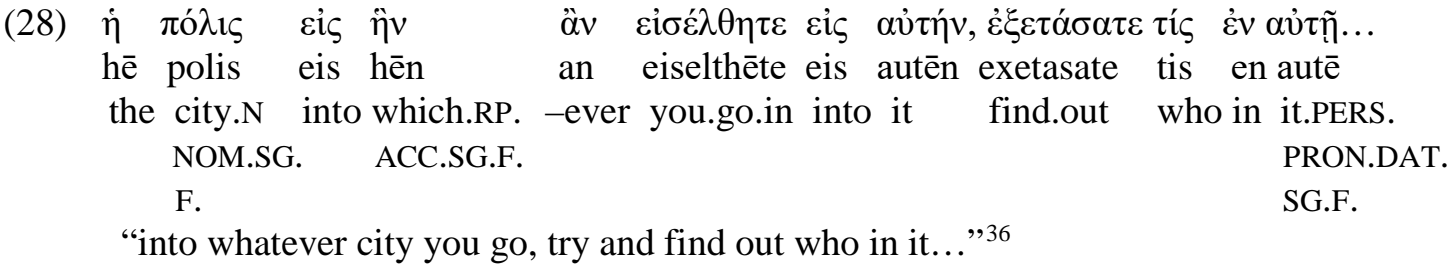

(Mt. 10:11 D)

The nominativus pendens also occurs in Latin, as in the following example of a correlative diptych (Lehmann 1984: 350):
(29) [Signa [quae nobis curasti]], ea sunt ad Gaietam exposita
statutes.N. which.RP. us you.got they.DEM. they. at Gaeta unloaded
NOM.PL. ACC.PL. PRON. NOM. were
NEUT. NEUT. $\quad$ PL.NEUT.
"the statutes which you got us, (lit. they) were unloaded at Gaeta."

\footnotetext{
${ }^{34}$ According to Lehmann (1984: 147), adjoining of subordinate sentences is not restricted to RSs, but also occurs in conditional sentences, where a similar interdependence exists between the protasis and apodosis. Adjoined RSs most commonly appear in the form of a korrelatives Diptychon (“correlative diptych”).

${ }^{35}$ Blass and Debrunner ([1013] 1967: 244) present examples such as (33) under the heading “Anakoluthon”, which indicates a breach in the construction.

${ }^{36}$ A nominative participle with the meaning of an RS sometimes also occurs in a prejoined position, e.g. in

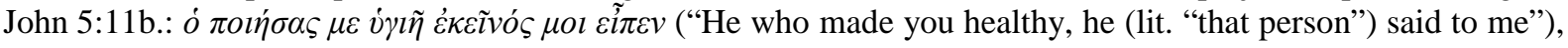
where the participle $\pi$ oı $\sigma \alpha \varsigma$ ("having made") is used in this sense.
} 
(Cic.At.1,2,3)

In some cases, a prejoined RS with an overt head-N could be circumnominal, as in the following example:

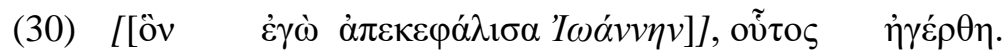

hon egō apekephalisa Iōannēn, houtos ēgerthē.

him.RP. I I.beheaded John.N this.DEM he.has.been.

ACC.SG. ACC.SG. NOM.SG. raised

M. $\quad$ M. M.

"John, whom I beheaded, he has been raised"

(Mk. 6:16b)

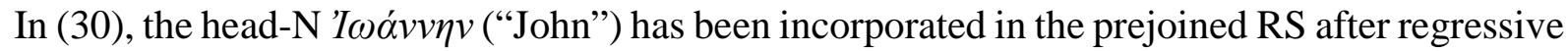
assimilation by the RP $\hat{o v}$ ("whom"), which is in the accusative case as the object of

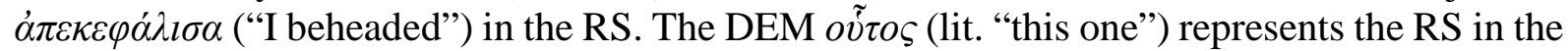
main sentence.

A prejoined RS could also be represented in the main sentence by a personal pronoun, as in the following example:

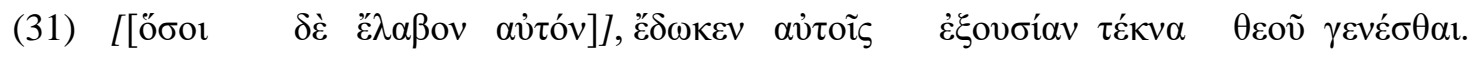 hosoi de elabon auton, edōken autois exousian tekna theou genesthai. whoever. but they. him he.gave to.them. right children of. to.become RP.NOM. received PERS.PRON. God
PL.M. $\quad$ DAT.PL.M.

"but whoever received him, he gave them the right to become God's children."

In this example, the RS is not represented by a DEM in the main sentence, but by the personal

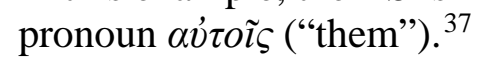

Adverbial RSs can also be prejoined in the format of a correlative diptych, as in the following example:

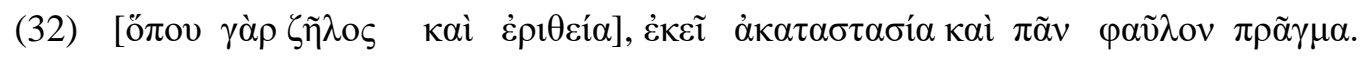
hopou gar zēlos kai eritheia, ekei akatastasia kai pan phaulon pragma. where for jealousy and selfish. there disorder and every evil thing ambition

"Where there is jealousy and selfish ambition, there is disorder and every kind of evil.”

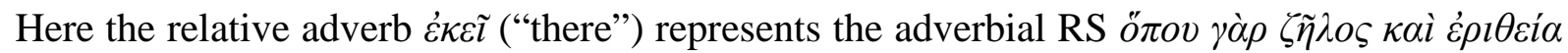
("where there is jealousy and selfish ambition") in the main sentence. ${ }^{38}$

\footnotetext{
${ }^{37}$ Boyer (1988: 236) regards pronouns such as $\alpha \dot{v} \tau o \tilde{\varsigma}$ (“to them”) as pleonastic in these cases. This does not seem

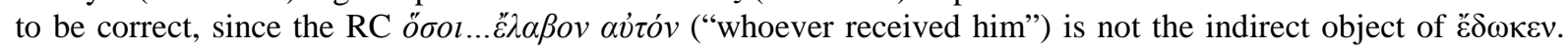
Prejoined RSs (also with overt antecedent) are not syntactically part of the main sentence.

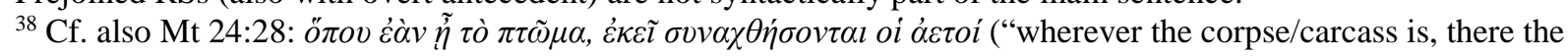
vultures will gather").
} 
The syntactic structure of prejoined RSs could be represented as in (33). The subscript numbers (1 and 2) refer to the RS and the main sentence, respectively:

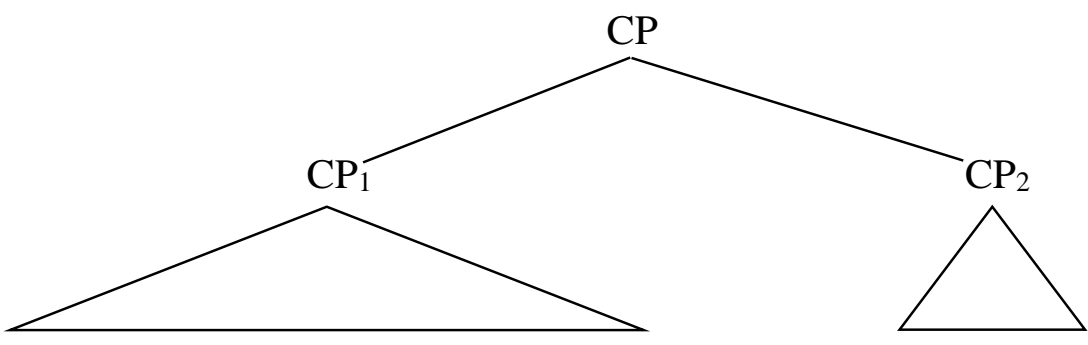

Lehmann (1984: 350) points out that, from the viewpoint of functional sentence perspectives, prejoined RSs, especially in the correlative diptych construction, are most suitable of all the types of RSs for Exposition (“exposition”). ${ }^{39}$ According to Lehmann (1984), topicalisation is one of the main functions of Latin RSs. In the correlative diptych in (29), for example, the RS (here with an antecedent) is prejoined. The communicative function of the nominativus pendens in (29) is that of exposition, about which the main sentence, ea sunt ad Gaietam exposita ("they were unloaded at Gaeta”), makes a predication.) $)^{40}$

Exposition also seems to provide a good description of the communicative function of the Greek prejoined RSs (with or without a head-N) in the examples in (26-28) and (30-32). In (26), for

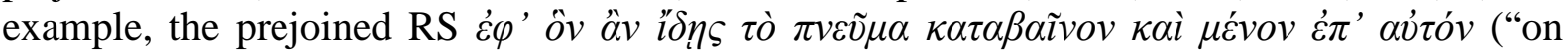
whoever you see the Spirit descend and remain") functions as exposition, about which a

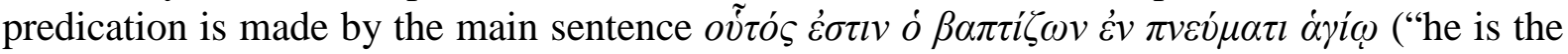
one who baptises with the Holy Spirit.”).

\subsubsection{Postjoined RSs}

The second type of adjoined RSs is postjoined RSs. In this case, (optional) extraposition of a postnominal RS has taken place to a position directly after the main sentence. Unlike an embedded RS, an extraposed RS is not a constituent of the main sentence. The following are some examples:

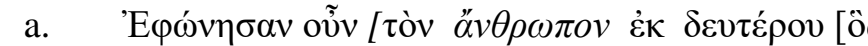
Ephōnēsan oun ton anthrōpon ek deuterou hos

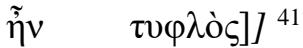
en typhlos they.called so the man.N for second who.RP. he.was blind ACC.SG.M. NOM.SG.M.

"So for the second time they called the man who had been blind."

\footnotetext{
${ }^{39}$ Exposition is defined by Lehmann (1984: 347) as "the frame within which a sentence holds", and as setting a "spatial, temporal or individual framework within which the main predication holds". Exposition always occurs at the beginning of a sentence, and is followed by the main predication. Lehmann (1984: 349) uses "topicalisation" as an overarching term that includes exposition and thematisation.

40 The nominativus pendens in Latin functions, according to Lehmann (1984: 350), exactly like exposition in Japanese or Chinese. For an example from Chinese, cf. Lehmann (1984: 349).

${ }^{41}$ The phrase $\dot{\varepsilon} \kappa \delta \varepsilon v \tau \varepsilon ́ p o v$ ("for the second time”) does not form part of the RC, as the brackets seem to indicate.
} 


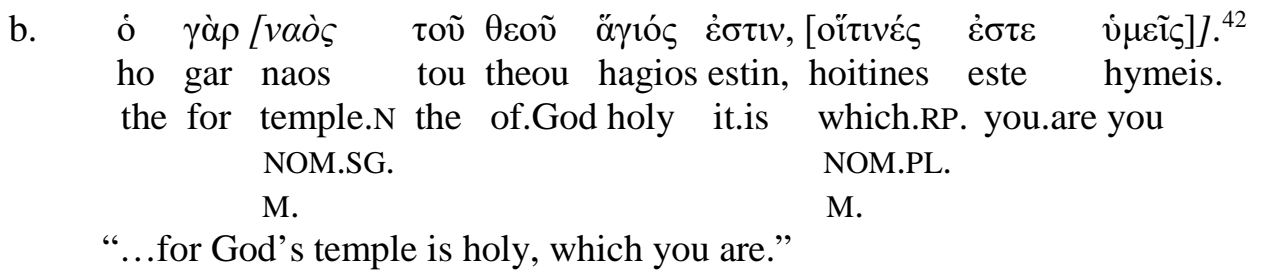

In (34a), the identifying RS has been extraposed from after its antecedent $\tau \grave{o} v \not \alpha v \theta \rho \omega \pi o v$ ("the man") to a position directly after the main sentence. In (34b), the appositive RS has been extraposed in a similar fashion to a position directly after the main sentence. In this example, the appositive RS functions on a text-semantic level like a main sentence and contributes to the overarching purpose of the text (cf. Lehmann 1984: 273). Extraposed appositive RSs share this characteristic with postnominal appositive RSs in sentence-final position. ${ }^{43}$ This interpretation of the RS in (34a) is supported by, among others, the Good News Bible (1979): "For God's temple is holy, and you yourselves are his temple.”

The syntactic structure of the sentence in (34a) could be represented in simplified form as in (35). The subscript numbers (1 and 2 ) in the diagram indicate the main sentence and the RS, respectively.

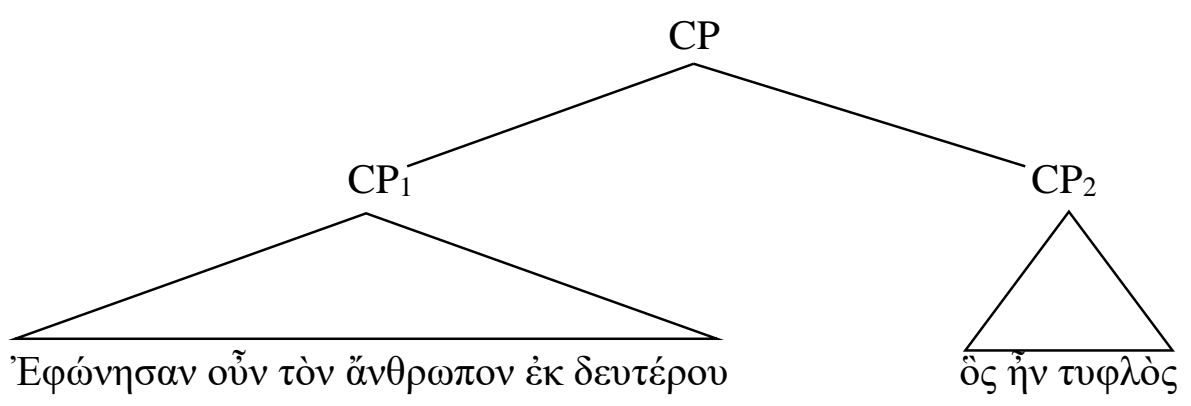

Extraposition of identifying RSs in English seems to proceed along similar lines. Compare the examples in (36a) and (36b):

(36) a. [The present [that my mother had sent me]] finally arrived.

b. The present finally arrived [that my mother had sent me]. ${ }^{44}$

In (36b), the identifying RS has been extraposed from its position directly after its antecedent, as in (36a), to a position after the main sentence.

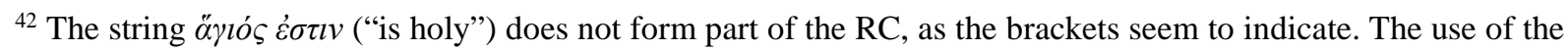

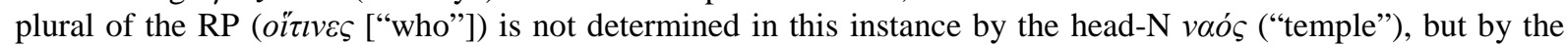
personal pronoun $\dot{v} \mu \varepsilon \tilde{\varepsilon} \varsigma$, to which the RP is linked by the copulative verb $\dot{\varepsilon} \sigma \tau \varepsilon$ ("you are") in the RS. The use of the plural could also be explained as a constructio ad sensum ("construction according to the sense"), since vaó $\varsigma$ ("temple"), although grammatically singular, refers in this context to more than one person.

${ }^{43}$ Compare with the example in (15b).

${ }^{44}$ According to Loetscher (1972: 53), extraposition can freely occur in identifying (in his terminology, restrictive) RSs in German, with the proviso that an element in the RS bears the sentential stress, as in the following example (where the sentential stress is underlined): Niemand hat eine Vorstellung von Mars, der noch nicht dort gewesen ist (lit. "Nobody has an idea of Mars, who has not been there").
} 
According to Radford (2009: 227) appositive RSs cannot be extraposed in English, as shown by the ungrammaticality of the sentence in (37b):

(37) a. A man has been arrested [who the police want to interview about a series of burglaries]. b. *John has been arrested [who the police want to interview about a series of burglaries]. ${ }^{45}$

\subsection{Sentential RSs}

In some RCs the antecedent of the RS is a sentence. This type of RS is rare in comparison with embedded and conjoined RSs. Compare the following example:

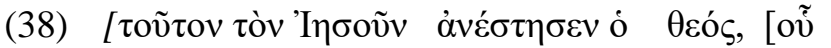
touton ton Iēsoun anestēsen ho theos, hou this the Jesus.N he.raised the God ACC.SG.

M.

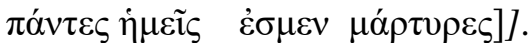
pantes hēmeis esmen martyres.

of which. all we we.are witnesses

RP.GEN.

SG. NEUT.

"God raised this Jesus, of which all of us are witnesses."

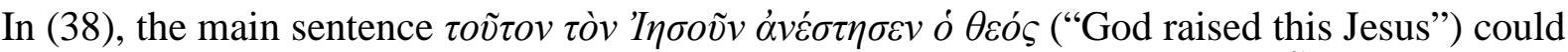
be taken as antecedent of the RS, which is introduced by the sentential RP or ("of which"). ${ }^{47}$ A sentential RS appears directly after its antecedent-sentence. In (38), the RS is in sentencefinal position, and it serves to express an appositive and continuous function, similar to that of an independent sentence continuing the discourse. Compare also the translation of the New International Version (1984): "God has raised this Jesus to life, and we are all witnesses of the fact." The function of the sentential RS in (38) corresponds to that of some postnominal appositive RSs in sentence-final position, and some postjoined appositive RSs. According to Lehmann (1984: 273), sentential RSs are always appositive, since they refer to sentences that, like proper Ns, indicate "unique” objects and are semantically definite. Therefore, a sentence cannot be the antecedent of an identifying RS.

\footnotetext{
45 According to De Vries (2006: 254), extraposition of appositive RSs is somewhat less productive in English, but not impossible, as in I met John yesterday, who I like a lot. He concludes that the construction is syntactically possible in general, but acceptability could be influenced by discourse factors (De Vries 2006: 255). According to Loetscher (1972: 53), in appositive (in his terminology, non-restrictive) RSs in German, extraposition can only take place over a final verbal element. Loetcher compares the grammatical Gestern habe ich auf der Bahnhofstrasse Elvis Presley angetroffen, der jetzt mit der Baronin von Ocs verheiratet ist ("I came across Elvis Presley yesterday, who is now married to the Baroness von Ochs, on Station Street”), with the ungrammatical *Rinder leben in allen Teilen der Welt, die zur Klasse der Paarhufen gehören (Horses, which belong to the class of split-hooves, live in all parts of the world").

${ }^{46}$ Other examples of sentential RSs in the NT are Ac. 3:15, 11:30; Gl. 2:10; Col. 1:29; 1 Pt. 2:8; Rv. 21:8, etc.

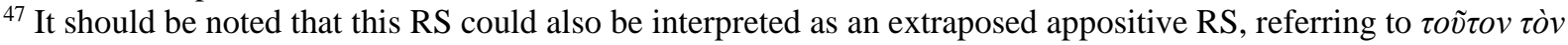
I $\eta \sigma o \tilde{v} v$ as antecedent, although the former interpretation seems preferable in the context. If regarded as an extraposed appositive RS, the translation would be: "God raised this Jesus, of whom we are all witnesses". The sentential RP $O$ " ("which”) is always neuter gender and singular. In English, sentential RSs are introduced by "which", as in the translation of the Greek text in (38). Sentential RPs in languages often have specific characteristics, compared to RPs in other types of RSs, for example German was ("which"), Latin id quod ("that which”), Italian il che or ciò che (“that, which”), and Persian cizi ke (“something, which”) (Lehmann 1984: 274).
} 
The syntactic structure of the RC in (38) could be represented as in (39), (where TP = tense phrase, $\mathrm{T}=$ tense, and $\mathrm{C}=$ complementiser $){ }^{48}$

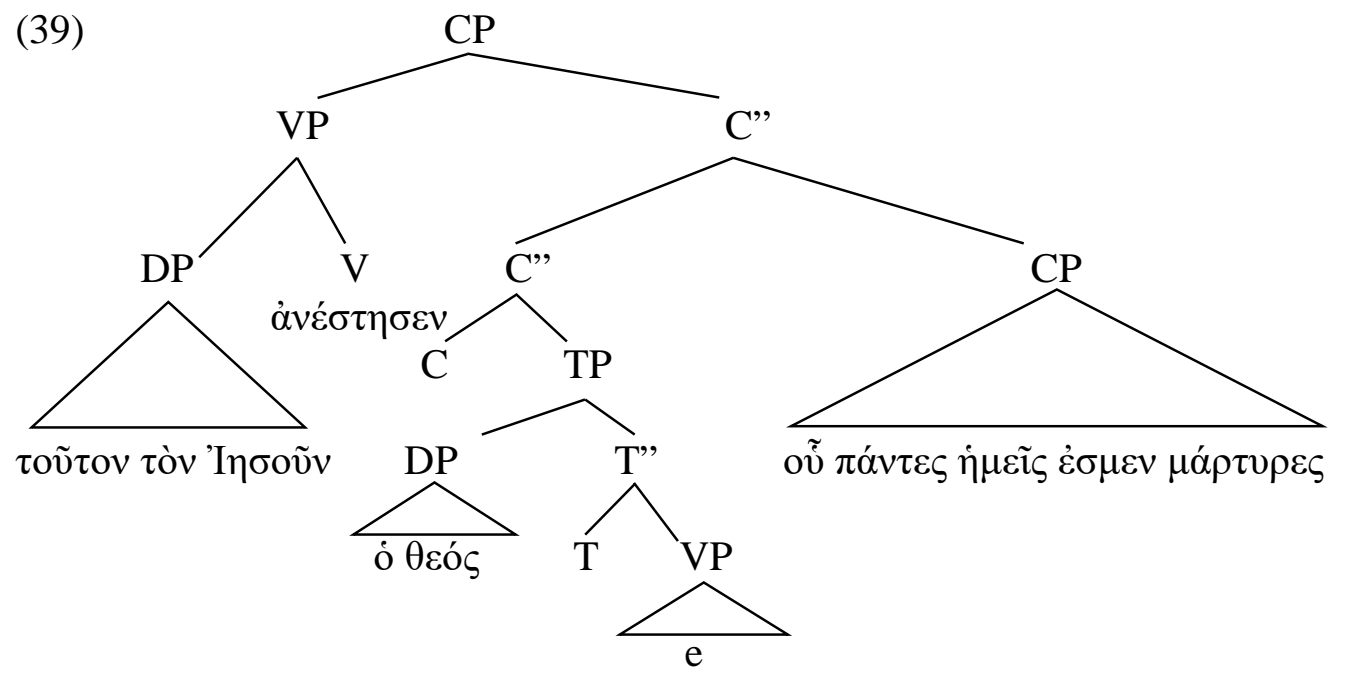

Sentential RSs can also be parenthetical, as in the following example:

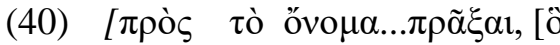

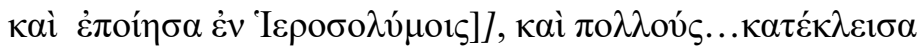
pros to onoma praxai, ho kai epoiēsa en Hierosolymois kai pollous katekleisa against the name to.do which. also I.did in Jerusalem and many I.shut.up RP.ACC. SG.NEUT.

"to do....against the name, which I also did in Jerusalem, and I shut up many"

(Ac. 26:9b.-10b.)

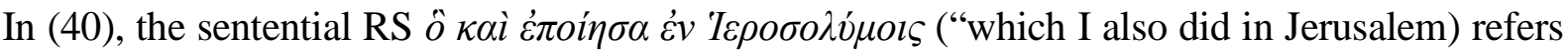

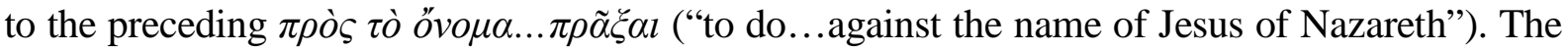
RS is parenthetical between $\pi \rho \grave{o} \varsigma$ ò övo $\mu \alpha . . \pi \rho \tilde{\alpha} \xi \alpha l$ ("to do....against the name") and $\kappa \alpha \grave{\imath}$

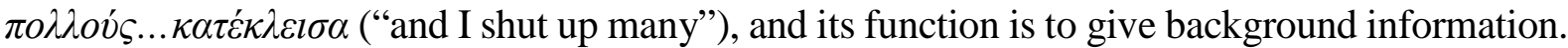

Sentential RSs also occur in some modern languages, such as English, German, Persian and Italian. Compare the English and German examples in (41a) and (41b), respectively. In both sentences the sentential RS is appositive and in sentence-final position:

(41) a. [Relative clause formation is obligatory in NPs, [which accounts for the difference in surface shape]]

b. [Luise ist eine Emanze, [was ich sehr bemerkenswert finde]].

Luise is an emancipated. which.RP. I very remarkable find woman ACC.SG.

NEUT.

"Luise is an emancipated woman, which I find very remarkable.” (Lehmann 1984: 274)

\footnotetext{
48 This structure incorporates two assumptions, simply as working hypotheses. Firstly, it is assumed that the VP

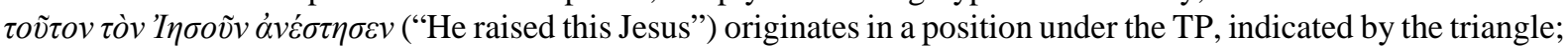
this VP is then moved to the sentence-initial position under CP, most likely by a focusing operation. Secondly, the

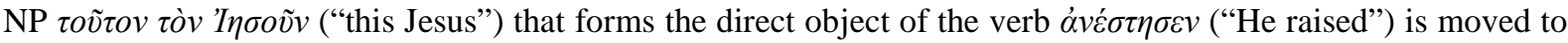
the initial position in the VP, presumably by means of some foregrounding rule (either before or after the VP was raised to the $\mathrm{CP}$ ).
} 
Parenthetical RSs also occur in German, as in the following example (Lehmann 1984: 274):

(42) Luise, [die eine Emanze ist - [was ich sehr bemerkenswert finde] - ...

Luise who.RP. an emancipated. is which.RP. I very remarkable find NOM.SG. woman ACC.SG.

F. $\mathrm{N}$.

"Luise, who is an emancipated woman - [which I find very remarkable] - ...”).

In (42), the sentential RS was ich sehr bemerkenswert finde is parenthetical, occurring between the appositive RS die eine Emanze ist ("who is an emancipated woman") and the rest of the sentence following the sentential RS. The RS die eine Emanze ist ("who is an emancipated woman") is the antecedent of the sentential RS, whose function is to provide background information.

\subsection{Conjoined RSs ${ }^{49}$}

A conjoined RS is in almost all aspects equivalent to an independent sentence that is joined to the preceding sentence by an RP. Compare the following example:

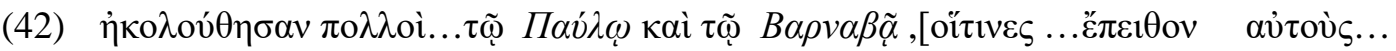

èkolouthēsan polloi tō Paulō kai tō Barnaba hoitines epeithon autous

they. many the Paul and the Barnabas who.RP. they. them

followed NOM.PL. persuaded

$\mathrm{M}$.

"Many followed Paul and Barnabas, who...persuaded them”

(Ac. 13:43b.)

In (42), the RS is introduced by oi"tuves ("who"), which is here equivalent to kaì oṽ they"). The RS is not subordinate as in all the above examples of RSs, but functions like a conjoined sentence. It does not have an antecedent in the real sense, but an anaphoric

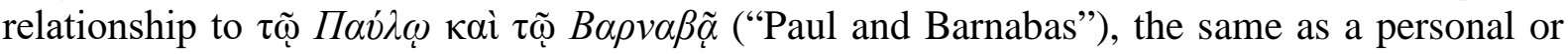
demonstrative pronoun would have. According to Lehmann (1984: 274) - who uses the term relativischer Anschluß ("relative joining") for this type of RS - this is the extreme form of an appositive RS, in the sense that it continues the discourse as an independent sentence. Relative joining is simply the substitution of a personal or demonstrative pronoun by an RP, a stylistic device that is used to increase the coherence of the text (Lehmann 1984: 274). The structure of the sentence in (42) could be presented as in (43)..$^{50}$ This structure is identical to the one in (35), except that, in this instance, both subscripts (1 and 2) refer to main sentences.

\footnotetext{
${ }^{49}$ Also referred to as “continuative” RSs, for example by Levinsohn (2000: 191), Du Toit (2015: 7), etc.

${ }^{50}$ However, Lehmann (1984: 275) remarks that it should be investigated whether there are structural characteristics that distinguish this type of RS from other RSs in sentence-final positions. It is generally agreed that coordination is a poorly understood phenomenon, and there is much debate in the literature on the syntax of coordinate constructions. A potential objection against the structure in (43), for instance, would be that the topmost CP seems to lack a unique head. For a detailed discussion of various issues relating to the syntax of coordination, cf. Zhang (2010).
} 
(43)

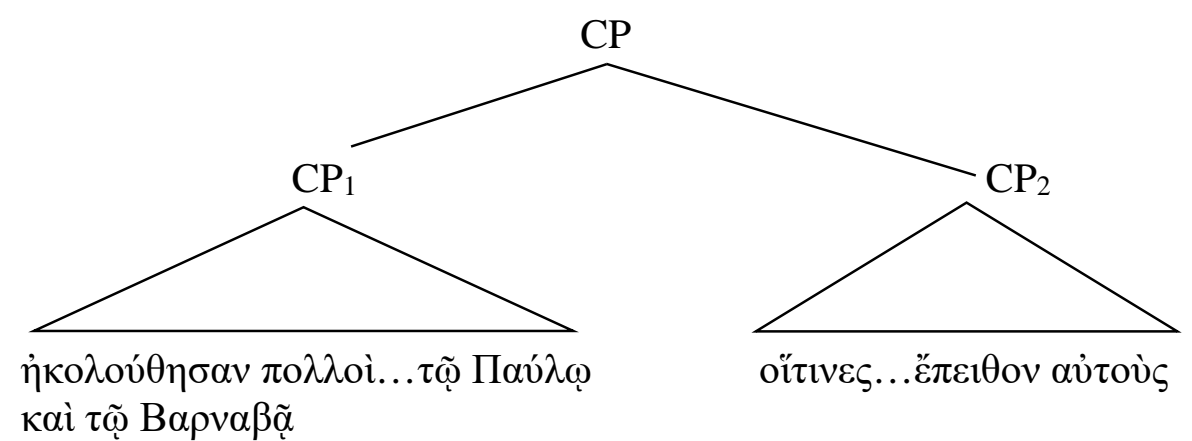

A similar construction occurs in Latin, as in the following example (Lehmann 1984: 274):

(44) At ego basilicus sum: [quem nisi oras] guttam non feres].

but I.PERS. kinglike I.am whom.RP. if.not you. trophy not you.will.

PRON. ACC.SG. ask carry

NOM.SG. $\quad$ M.

"But I am kinglike: if you do not ask me (lit. "whom if you do not ask"), you will not carry a trophy.”

(Pl.Ru. 434)

A conjoined RS can occur either directly after the element to which its RP has an anaphoric relationship, as in (42), or after the sentence containing the element, as in the following example:

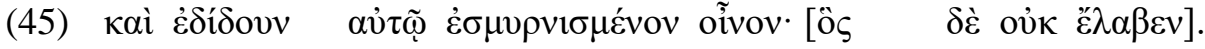

kai edidoun autō esmyrnismenon oinon hos de ouk elaben

and they.tried. to. mixed.with. wine he.RP. but not he.took

to.give him myrrh NOM.SG.

M.

"and they tried to give him wine mixed with myrrh to drink, but he did not take it."

(Mk. 15:23)

In this case, the anaphoric relationship obtains between the RP ő ("he”) and the personal pronoun $\alpha \dot{\tau} \tau \tilde{\varphi}$ (“to him”).

It should be noted that conjoined and sentential RSs are not mutually exclusive. Compare the following German example (Lehmann 1984: 274):

(46) Dieser Wagen ist nicht verbesserungsfähig. [Weshalb wir ihn unverändert weiterbauen.]

This car is not improvable which.is. we it without. keep.building

why. REL. changes

ADV.

"This car is not improvable. Which is why we keep building it without changes.”

The RS in (46) is an independent sentence, and it would not matter semantically if deshalb ("therefore") were to be substituted for weshalb ("which is why") (Lehmann 1984: 274). The RS is also a sentential RS, since its RP weshalb ("which is why") refers to the whole preceding sentence. 


\section{Synthesis}

Relative constructions in the Greek NT have a variety of syntactic features, all of which have counterparts in some modern (or other ancient) languages, despite the differences. The RS is mostly postnominal, and the RP-type is used in those cases for encoding the role of the coreferential element in the RS. RSs are highly accessible to relativisation and RPs occur in a variety of syntactic functions, e.g. subject, direct object, etc. Nominal elements serve mostly as antecedents of RSs, although sentences also appear in that function.

A variety of syntactic types of RSs can be distinguished, which include the prenominal participial, postnominal finite/participial, circumnominal, free relative, adverbial, prejoined, postjoined, sentential and conjoined types. These can be linked in a systematic way to the four functions of RSs in the New Testament, i.e. identifying, appositive, adverbial and continuative. This is illustrated in Figure 1 below (syntactic types of RSs are presented in blocks, whereas their respective functions are indicated in italics below the lowest boxes in each hierarchy).

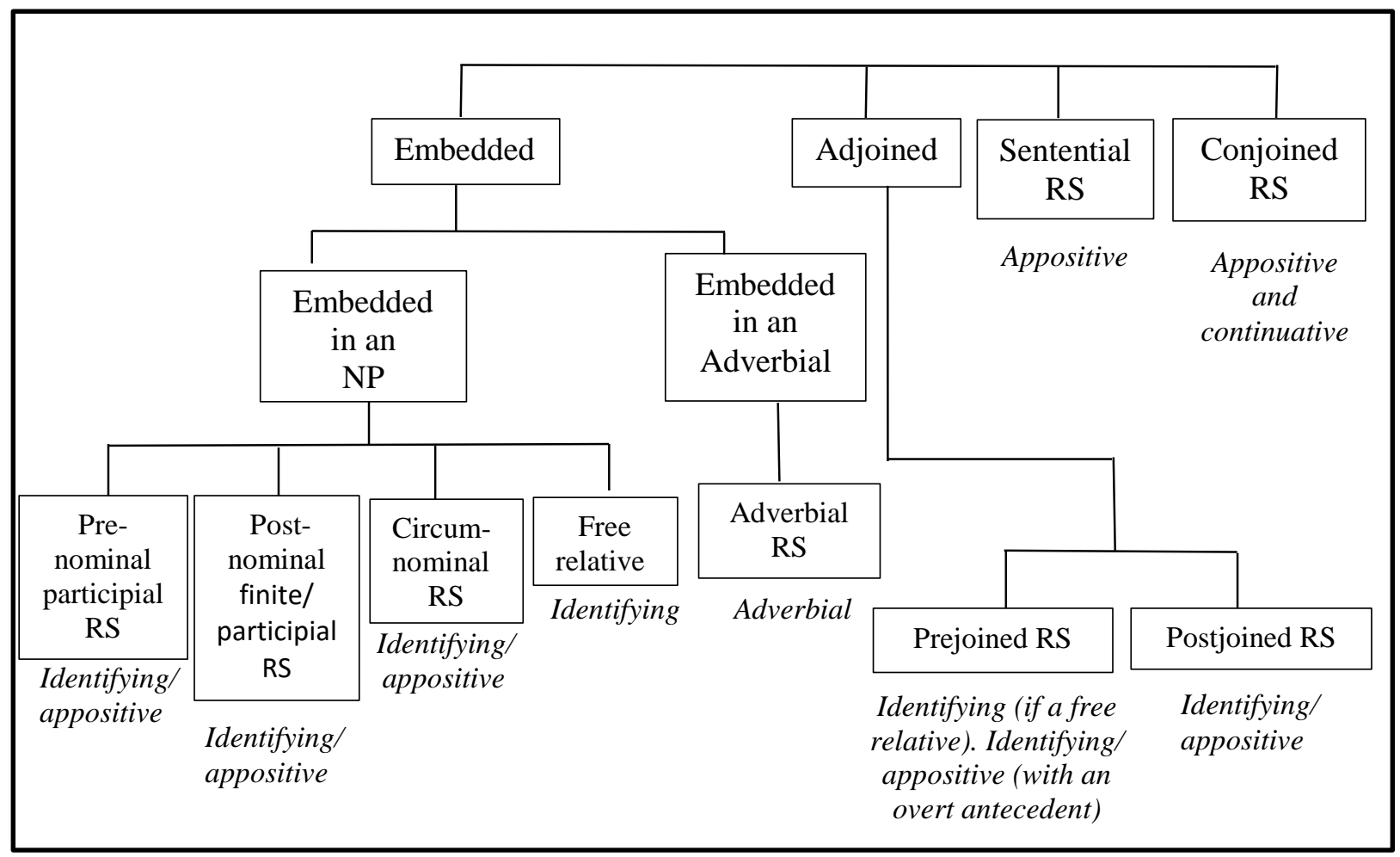

Figure 1: Syntactic types of RSs in the Greek NT

Some RSs also play a role in communicative strategies. Prejoined RSs, for example, are most suitable for exposition and theme-building, especially in the correlative diptych construction.

\section{Acknowledgement}

I would like to express my gratitude to Johan Oosthuizen of the Department of General Linguistics, Stellenbosch University, for his valuable input into this paper. 


\section{References}

Aland, K. 1983. Vollständige Konkordanz zum Griechischen Neuen Testament. Unter Zugrundelegung aller modernen kritischen Textausgaben und des Textus Receptus, in Verbindung mit H. Riesenfeld, H.-U. Rosenbaum, C. Hannick und B. Bonsack. Neu zusammengestellt unter Leitung von K. Aland. Band I(2). A- $\Omega$. Berlin und New York: Walter de Gruyter.

Abney, S. 1987. The English noun phrase in its sentential aspect. Doctoral dissertation. MIT.

Blass, F. and A. Debrunner. [1913] 1967. A Greek grammar of the New Testament and other early Christian literature, transl. and rev. of the 9th-10th German edition. entitled Grammatik des neutestamentlichen Griechisch by R.W. Funk, incorporating supplementary notes of A. Debrunner. Chicago: The University of Chicago Press/Toronto: The University of Toronto Press.

Blass, F. and A. Debrunner. [1913] 1979. Grammatik des neutestamentlichen Griechisch. 14. Aufl., völlig neubearbeitet und erweitert von F. Rehkopf. Göttingen: VandenHoeck.

Boyer, J.L. 1988. Relative clauses in the Greek New Testament: A statistical study. Grace Theological Journal 9(2): 233-256.

Chomsky, N. 1977. Essays on form and interpretation. The Hague: Mouton.

Chomsky, N. 2006. Approaching UG from below. Ms. published in U. Sauerland and H.-M. Gärtner (Eds.) 2007. Interfaces and Recursion = Language? New York: Mouton de Gruyter. pp. 1-29.

Comrie, B. 1989. Langage universals and linguistic typology. Syntax and morphology. 2nd edition. Chicago: The University of Chicago Press.

Comrie, B. and E.L. Keenan. 1979. Noun phrase accessibility revisited. Language 55: 649-664.

Culicover, P.W. 1997. Principles and parameters. An introduction to syntactic theory. Oxford Textbooks in Linguistics. Oxford: Oxford University Press.

Danker, F.W. 2000. A Greek-English lexicon of the New Testament and other Early Christian Literature. 3rd edition. Chicago et al.: University of Chicago Press.

De Vries, M. 2006. The syntax of appositive relativization: On specifying coordination, false free relatives, and promotion. Linguistic Inquiry 37(2): 229-270.

Du Toit, H.C. 1984. Semantiek en sintaksis van relatiewe sinne in die Griekse Nuwe Testament. Unpublished D.Litt. thesis. University of Pretoria.

Du Toit, H.C. 2014. The semantics and syntax of relative sentences in the Greek New Testament. Paper presented at the 69th General Meeting of the SNTS. Szeged, Hungary. 
Du Toit, H.C. 2015. Exploring the function of relatives sentences in New Testament Greek. HTS Theological Studies 71(1): 1-8.

Fiorentino, G. 2007. European relative clauses and the uniqueness of the RP type. Rivista di Linguistica 19(2): 263-291.

Haegeman, L. 1994. Introduction to Government and Binding Theory. 2nd edition. Oxford: Blackwell Publishers.

Hays, M.E. 2014. An analysis of the attributive participle and the relative clause in the Greek New Testament. Ph.D. dissertation. Concordia Seminary, St. Louis, U.S.A.

International Bible Society. 1984. New International Version. Grand Rapids, Michigan: Zondervan Publishing House.

Jackendoff, R. 1979. X-syntax: a study of phrase structure. Linguistic Monograph Series 2. Cambridge: MIT Press.

Keenan, E.L. 1974. The functional principle: generalizing the notion of "Subject-of". In M. Lagaly, R. Fox and A. Brook (Eds.) Papers from the tenth regional meeting of the Chicago Linguistic Society. Chicago: Chicago Linguistic Society. pp. 298-309.

Keenan, E.L. 1975. Logical expressive power and syntactic variation in natural language. In E.L. Keenan (Ed.) Formal semantics of natural language. Papers from a colloquium sponsored by the King's College Research Centre, Cambridge. Cambridge et al.: Cambridge University Press. pp. 406-421.

Keenan, E.L. 1976. The logical diversity of natural languages. In S.R. Harnad, H.D. Steklis and J. Lancaster (Eds.) Origins and evolution of language and speech. New York: New York Academy of Sciences (Annals of the N.Y. Academy of Sciences, 280). pp. 73-91.

Keenan, E.L. and B. Comrie. 1977. Noun phrase accessibility and universal grammar. Linguistic Inquiry 8(1): 63-99.

Keenan, E.L. and B. Comrie. 1979. Data on the noun phrase accessibility hierarchy. Language 55(2): 333-351.

Lehmann, C. 1984. Der Relativsatz: Typologie seiner Strukturen; Theorie seiner Funktionen; Kompendium seiner Grammatik. Tübingen: Gunter Narr Verlag. (Language Universal Series 3).

Oosthuizen, J. 2013. Obligatory reflexivity in a Minimalist grammar of Afrikaans. Stellenbosch Papers in Linguistics PLUS 42: 205-241.

Porter, S.E. 2013. Translation, exegesis, and 1 Thessalonians 2.14-15. Could a comma have changed the course of history? The Bible Translator 64(1): 82-98.

Radford, A. 2009. Analysing English sentences. A minimalist approach. New York: Cambridge University Press. 
Robertson, A.T. 1919. A grammar of the Greek New Testament in the light of historical research. Rev. and enlarged 3rd edition. Cambridge: Cambridge University Press.

Schwartz, A. 1971. General aspects of relative clause formation. Working Papers on Language Universals 6: 139-171. Stanford University Language Universals Project.

Van Valin, R.D. and R.J. LaPolla. 1997. Syntax. Structure, meaning and function. Cambridge: Cambridge University Press.

Voelz, J.W. 2006. Participles, Part 3. Concordia Journal (October): 401-403.

Wallace, D.B. 1996. Greek grammar beyond the basis. An exegetical syntax of the New Testament. Grand Rapids: Zondervan Publishing House.

Zhang, N.N. 2010. Coordination in syntax. Cambridge Studies in Linguistics. Cambridge: Cambridge University Press. 